\title{
Sociedade do espetáculo adiado: apontamentos sobre educação na cidade febril
}

\begin{abstract}
Resumo: Este artigo objetiva desenvolver alguns apontamentos sobre os impactos da pandemia de COVID-19 para a educação. Parte da suspensão das características da sociedade do espetáculo em meio às mudanças operadas pela crise sanitária e seus desdobramentos econômicos, sociais, culturais e, sobretudo, nos modos de subjetivação contemporâneos. O novo cenário agudiza as segmentações molares e moleculares da dívida, da securitização e o esvaziamento das instâncias políticas, forçando ainda mais a busca por territórios abertos e a necessidade de outros campos de visualidade. Entendendo a pandemia como um ponto de vista, habitar a interioridade desta perspectiva nos ajuda a compreender não só as sombras da modernidade residual, como os processos de subjetivação que exercitam outras formas de atenção, uma espécie de fúria dos vaga-lumes na célebre imagem proposta por Pasolini. Para além das formas dominantes de educação, é esse quase-mundo de uma educação informe que se abre com o inferno conjuntural do momento. Algumas dessas contra-utopias e seu iluminismo das sombras arrasta nossos olhos para frestas que, se alargadas, desfazem a luz branca das utopias e distopias do poder. Atravessando algumas dessas fogueiras difusas, elencamos algumas reverberações que a pandemia de COVID-19 evoca, como linhas abertas ao pensamento violentado por sua perspectiva e passível de formulações vindouras, o que chamamos de efeito "Joker" na sociedade do espetáculo adiado.
\end{abstract}

Palavras-chave: Pandemia. Sociedade do espetáculo. Cidade febril. Educação do informe.

\section{Introdução: sociedade do espetáculo adiado}

Se a origem do espetáculo é a perda da unidade do mundo, como definiu Debord (2000) no final dos anos 1960, a pandemia de COVID-19 teve o estranho papel de organizar as tragédias dispersas do mundo contemporâneo e intensificá-las. O milenarismo invertido (JAMESON, 2000) do único e enorme espetáculo que adiou todos os maiores espetáculos da Terra. "Voltar à normalidade", dizem. Mas o que é voltar? Precisamos saber onde estivemos e que trajeto construímos para alimentar o desejo de voltar. "Estivemos no normal", dizem. Mas o que foi o normal? Que trajeto satisfez sua composição passageira, não perceptível de sua fugaz condição? "O fim do mundo é um tema aparentemente interminável - pelo menos, é claro, até que ele aconteça". (CASTRO; DANOWSKI, 2014, p. 11) Ele aconteceu, que fazer?
Marcio Tascheto da Silva Universidade Franciscana - UFN tascheto@ufn.edu.br

Os últimos anos têm sido marcados por um milenarismo invertido segundo o qual os prognósticos, catastróficos ou redencionistas, a respeito do futuro foram substituídos por decretos sobre o fim disto ou daquilo [...]. (JAMESON, 2000, p. 27)

Esta sociedade que suprime a distância geográfica, recolhe interiormente a distância, enquanto separação espetacular. (DEBORD, 2000, p. 11)

Perceber no escuro do presente essa luz que procura nos alcançar e não pode fazê-lo, isso significa ser contemporâneo.

(AGAMBEN, 2013, p. 65) 
"Cegos de tanto ver coisas [...]" (WISNIK, 2018, p. 307), os habitantes da sociedade do espetáculo se veem a si mesmos imersos em uma grande nuvem espessa. Formas e cidades vulturinas como nas imagens de Goeldi. (RUFINONI, 2006) Toda uma espécie dedicada ao louvor às sombras como proposto nos distantes anos 1930, por Tanizaki (2017). Ou ainda, nas esfumaçadas obras de Olafur Eliasson e seus materiais elementares, realidades vaporosas e misteriosas. (WISNIK, 2018) Em suas variações, parecem dizer um basta na "sociedade da hipervisibilidade" (WISNIK, 2018) e a voracidade dos seus holofotes. Um basta no par luz e poder antagonizados por sombras e franjas, tendências e sobras de outras temporalidades políticas.

Diante desse tempo de adiamento da sociedade do espetácu1o, nos perguntamos quais os impactos na educação em meio a cidade febril? Questão que desencadeia uma série de tentativas de entendimento da suspensão da sociedade do espetáculo e seus derivativos. Como se a nuvem de vaga-lumes descrita por Pasolini, imagem resistência a fascista Itália da sua juventude, se atualizasse nas agruras reunidas da pandemia de COVID-19. Vivemos em plena fúria dos vaga-lumes.

Nossa aposta é que a segmentação quase consensual das diferentes possibilidades de educação formal, não formal e informal, é assombrada pela educação do informe, sintetizada na dança urbana caótica do personagem Coringa do cineasta Todd Phillips. Ainda não sabemos qual será a educação pós-pandêmica, mas podemos extrair alguns de seus signos e enigmas. O que podemos especular, na esteira de Castro e Danowski (2014), é se ainda há mundo por vir? Ou, nas provocações de Berardi (2019), o que virá depois do futuro?

Este artigo pretende percorrer algumas dessas searas escavadas na cidade febril, acompanhando a realidade de suas velhas e novas segmentações, o trabalho das linhas que se bifurcam em maquinações difusas e o tráfico de novas percepções indeléveis que o ponto de vista da pandemia vem produzindo. (LAPOUJADE, 2017) Situa a discussão no terreno das experimentações pedagógicas entre cidade e educação, intensificando a atenção da sociedade do espetáculo adiado para os territórios urbanos e suas mutações nas temporalidades liberadas pela pandemia de COVID-19. 


\section{A fúria dos vaga-lumes}

Em primeiro lugar, a pandemia força o atravessamento de linhas, bloqueia, abre novas e reforça velhas segmentações. Segundo Cassiano e Furlan (2013, p. 373),

Deleuze e Guattari apontam três tipos de linhas que compõem nossas relações: as de segmentaridade dura, características dos grandes conjuntos molares ou estratos, como as classes sociais e os gêneros; as de segmentaridade maleável, caracterizadas por relações moleculares de desestratificações relativas, com velocidades acima ou abaixo dos limites da percepção, e que, ao contrário dos grandes movimentos e cortes que definem os estratos, compõem-se de elementos rizomáticos, esquizos, sempre em devir, fluxos sempre em movimento que retiram o homem da rigidez dos estratos; e as linhas de fuga, que se caracterizam por uma ruptura com os estratos ou sua desestratificação absoluta.

É preciso compreender como funciona essa malha de intersecções que é desencadeada pelas forças de reconversão subjetiva dentro da imanência da crise. Somos segmentarizados por todos os lados e em todas as direções. O homem é um animal segmentário. À segmentaridade pertence todos os estratos que nos situam espacialmente. Trabalhar, habitar, brincar, adoecer, morrer. A casa é dividida em cômodos. Cozinha, quartos, banheiros, salas, varandas, corredores. O lugar de dormir, amar, descansar, sofrer, sonhar, ter pesadelos, trabalhar. O lugar de comer, o lugar de higienizar-se, circular, ser um sonâmbulo em sua própria casa. Segmentações ainda mais capilarizadas pela intensificação do isolamento social, do borramento de fronteiras entre tempo de trabalho e tempo lazer, a casa-trabalho como invólucro da mobilização da vida para a produção.

Somos segmentarizados em nossos bairros, ruas, na ordem da cidade vazia. Somos segmentarizados nas fábricas, escritórios, salas de aula, no toque de recolher, na quarentena das horas e meses intermináveis de espera. Somos segmentarizados binariamente, homem e mulher, velhos e novos, crianças e adultos, grupos de risco ou não, com comorbidades ou não. Somos segmentarizados circularmente, "as ocupações de meu bairro, de minha cidade, de meu país, do mundo... somos segmentarizados linearmente, numa linha reta, em linhas retas" cada segmento representando 
um processo, um episódio "mal acabamos um processo e já estamos iniciando outro, demandantes ou demandados para sempre, família, escola, exército, profissão". (DELEUZE, GUATTARI, 2004, p. 84) A vida dividida em fases. Há tempo para isso e para aquilo. Não há tempo. Sempre recomeçando algo. Nunca terminando nada, em um processo incessante de compromissos e fazeres. Somos segmentarizados em linhas cada vez mais duras. Se é verdade que o esquadrinhamento dos tempos e dos espaços já preexistia a pandemia, a cidade febril intensifica ainda mais essas máquinas de segmentação características dos grandes conjuntos molares.

"Toda a sociedade, mas também todos os indivíduos, são, pois, atravessados por duas segmentaridades ao mesmo tempo: uma molar e outra molecular." (DELEUZE; GUATTARI, 2004, p. 90) Na cidade, temos linhas que estabelecem planos territoriais, organizações espaciais, planejamentos de ruas e avenidas. Espaços privados e espaços públicos, temos segmentações molares de todas as ordens, dado que não vivemos em um espaço liso. Estriamentos e posições diversas nos perfazem habitantes de cruzamentos, paradas. Ao mesmo tempo, nos interessam as macropolíticas da cidade, seus planos diretores, seus estatutos, direitos, suas grandes questões sobre saneamento, segurança, mobilidade. Segmentações molares em um conjunto díspar e simultâneo, conforme o emaranhamento das linhas de segmentação supracitas. Por outro lado, temos um conjunto molecular de atravessamentos, micropolíticas cotidianas. "Micro perceptos inconscientes, de afectos inconscientes, de segmentações finas, que não captam ou não sentem as mesmas coisas, que se distribuem de outro modo, que operam de outro modo". (DELEUZE, GUATTARI, 2004, p. 90) Porque não basta definir as segmentações apenas na dimensão molar, com suas divisões enrijecidas e no plano geométrico do desenho urbano, é preciso compreender também suas segmentações finas que operam na dimensão molecular.

Nesse duplo processo de segmentações, molar e molecular, que precisamos situar o ponto de vista da pandemia. Não o nosso ponto de vista sobre a pandemia, mas o ponto de vista que circula e descentra o sujeito do seu lugar anterior. (LAPOUJADE, 2017) A fúria dos vaga-lumes, conforme a experiência/imagem de Pasolini, é a radical descentralidade da luz dos holofotes da sociedade do espetáculo e seu poder de visualidade, para uma expressiva proliferação de pequenas fogueiras na noite da História. Algo que nos 
coloca no processo aberto de ver e enunciar não só outras segmentações impostas, mas também existências mínimas que circulam o direito à cidade por dentro do ponto de vista dos personagens que insistem em continuar em cena e intensificar realidades ofuscadas.

São exemplos dessas opacidades na educação e na cidade (que o ponto de vista da pandemia faz ver com maior clareza a desigualdade social, de gênero e racial), a exclusão digital (sendo um dos exemplos mais polêmicos a realização do Enem em um contexto de distanciamento ainda maior da igualdade de oportunidades dos estudantes), o isolamento social e a questão da moradia (quem pode ficar em casa? Em que condições?), a densidade das metrópoles brasileiras (aceleração do contágio por meio da super aglomeração demográfica), a precariedade do trabalho (as discussões sobre renda universal básica), o acesso aos serviços de saúde, mobilidade, entre outras questões estruturais e conjunturais que tornam mais aguda a crise sanitária ao mesmo tempo que dão visibilidade a questões latentes pré e durante a pandemia.

\section{Depois da educação: há mundo por vir?}

O que nos legará todas essas questões que as "aprendizagens" da pandemia vêm desdobrando? Abrirá espaço para existências que mobilizam outras visualidades na sociedade do espetáculo adiado? Como quebrar com o ciclo da cidade esgotada pela solidão, terror e isolamento e a desigualdade que a pandemia põe a nu? Que outras pedagogias podemos construir na cidade febril? Capaz de reinventar não só a cidade como as nossas próprias vidas em meio à crise sanitária?

[...] a questão do tipo de cidade que queremos não pode ser separada da questão do tipo de pessoas que queremos ser, que tipos de relações sociais buscamos, que relações com a natureza nos satisfazem mais, que estilos de vida desejamos levar, quais os nossos valores estéticos. O direito à cidade é, portanto, muito mais do que o direito de acesso individual ou grupal aos recursos que a cidade incorpora: é um direito de mudar e reinventar a cidade mais de acordo com os nossos mais profundos desejos. (HARVEY, 2014, p. 28)

Mais do que um desejo produzido pela soma dos desejos dos indivíduos, o propósito de reinventar a cidade passa pela composição 
de um complexo de singularização que envolve sistemas afetivos, perceptivos, cognitivos, ou seja, todo um outro campo de visualidades. Processos de subjetivação que vão além das formas individuadas, se insinuando em uma economia desejante que não depende somente da correlação de forças molares, dos sujeitos e seus jogos representacionais. Tampouco depende somente das grandes questões molares, mas de linhas minoritárias que abrem diferentes questionamentos por dentro das territorializações capitalistas. Como construir a cidade que queremos em meio à especulação imobiliária e à espetacularização urbana? As remoções e gentrificação, a política dos megaeventos? Como projetar os nossos mais profundos desejos na contracorrente de um imaginário urbano capturado na semiótica capitalista e despotencializado? Como podemos pensar as vidas urbanas longe dessa "cidade maior" das maquinações do capital, colocadas a nu pela crise sanitária?

O termo 'cidade' tem uma história icônica e simbólica profundamente inserida na busca de significados políticos. A cidade de Deus, a cidade edificada sobre um morro, a relação entre cidade e cidadania - a cidade como objeto de desejo utópico, como lugar distintivo de pertença em sua ordem espaço-temporal em movimento perpétuo -, tudo isso confere à cidade um imaginário que mobiliza um significado político crucial. (HARVEY, 2014, p. 22)

Diferentemente de Harvey (2014), não se trata da busca por significados políticos sobre a cidade febril, um novo transcendente capaz de organizar o que está disperso politicamente. O imaginário crucial que confere à cidade essa possibilidade de fabulação revolucionária, de invenção de formas de vida, é a heterogeneidade de agenciamento que é capaz de mobilizar todos os tipos de corpos. Sobretudo, a partir dos pontos de vista já existentes, na imanência das lutas e nos processos que a pandemia vem acelerando ou bloqueando.

A cidade compõe-se como uma megamáquina de produção antropológica, funcionando como um caldo de relações técnicas, naturais, sociais e psíquicas em constante interação. Portanto, não se trata de encontrar o significado político da cidade, mas de dar ensejo a processos de subjetivação multicomponencial, que permitam maquinações urbanas por todos os lados, bricolagens e aglutinações espaciais de todas as ordens. Mais do que utopias 
urbanas, mais do que as imagens que a pintura, a fotografia, o cinema, a religião e o próprio urbanismo não cansaram de produzir sobre a cidade, como podemos visualizar as "cidades menores", essas que nos escapam e se apresentam de outra maneira na guinada promovida pelo ponto de vista da pandemia? As cidades dentro da cidade, as microcidades, as inúmeras heterotopias que não param de surgir. Como podemos fugir do gordo urbanismo racionalizante sobre a cidade, que não se deixa atravessar pelas diversas possibilidades de fazer cidade e suas certezas biopolíticas? Suas redes de poder que mais se aproximam do uso da cidade como uma grande fábrica social soldando discursos antidemocráticos no avesso do direito à cidade? Sobretudo agora, em que as contradições sociais e políticas se ampliam de forma capilar nas malhas da realidade, abrindo descontinuidades onde só víamos morosidade.

Esse "algo diferente" não decorre necessariamente de um projeto consciente, mas simplesmente daquilo que as pessoas fazem, sentem, percebem e terminam por articular à medida que procuram significados para sua vida cotidiana. Essas práticas criam espaços heterotópicos por toda parte. Não precisamos esperar a grande revolução para que esses espaços venham a se concretizar. (HARVEY, 2014, p. 22)

A vertigem de questões que situam a cena urbana como um território aberto antes, durante e pós-pandemia, deve conduzir ao desejo de resistências dispersas a essa cidade maior, a fim de pensar e mostrar suas heterotopias capazes de mobilizar enigmas informes. O conceito de multidão em Negri e Hardt (2005) traz linhas de escape para a fabulação desse processo que visa encontrar, contornar e apreender esses espaços outros, os quais não param de surgir nos istmos molares e moleculares do tecido urbano. O que pode a multidão dispersa na cidade febril? A multidão embaralhada no cotidiano, no correr tedioso dos dias de isolamento e postergação? O que pode essa multidão rarefeita, sem notícia e sem revolução que não o devir lento e imperceptível das mudanças mais irreversíveis, de um mundo que resta por vir? O que pode essa educação informe que nasce do aprofundamento das desigualdades, mas também do aceleramento da apropriação de novas tecnologias? O que podem as agendas do comum como a renda universal básica, as novas articulações entre o público e o privado, a potência da 
liberação de outras circulações e os territórios educativos que se constituem nessa imanência pandêmica?

Como captar os gestos multituordinários dispersos? Como perceber as micropolíticas cotidianas no cenário da cidade que adoece e se cura? Que suspensões acontecem na velo-cidade dos corpos assujeitados pelo fluxo desterritorializante do agenciamento da crise sanitária global? Como perceber essas pequenas insubordinações aleatórias das vidas que transitam? Que fazeres urbanos são costurados no cotidiano invisível dos devires minoritários, de redes de solidariedade que se forjam nas ruas e redes? Inseridos intersticialmente nos escaninhos da cidade, em suas lutas, seu vai e vem, seus fluxos e cruzamentos, seus lugares de permanência e isolamento. Seu metabolismo febril, nos sons abafados das ambulâncias, suas buzinas e luzes, enfim, na imanência urbana de uma cidade sitiada.

Diante da crise urbana e sanitária, a pergunta por uma cidade silenciosa, em segredo: quem a reinventa? Quem são esses sujeitos que reviram as ruas e embaralham os planejamentos? Que buscam os espaços de sua existência em meio ao mar de esmagamentos hodiernos? Como fazem espaços, vidas e perspectivas? Como irrompem lugares e matizes de uma cidade escondida, invisível e, ou, melhor, invisibilizada? Qual a potência desses espaços e desses sujeitos para pensar heterotopias pedestres, como "sementeira para o direito à cidade" (HARVEY, 2014, p. 23), o fazer comum da multidão dispersa em meio a tragédia que reúne e adia? Uma nova percepção que parece circular como um anjo que ronda o mundo. Desta vez, sem a tonalidade de uma bandeira definida e nem ao menos do "que fazer" diante da História. Um anjo informe, sem asas para abrir para os escombros do passado, imobilizado na suspensão do espetáculo. Nos cabe perceber seus movimentos quase imperceptíveis.

Esses sujeitos que se insurgem contra a ordem de endividamentos absurdos nas moradias, na mobilidade, nos serviços, na luta por hospitais e pela própria vida. Esses sujeitos que não acreditam nas informações rápidas e suas respostas aviltantes, nas peças publicitárias de automóveis, nos cartazes de uma vida feliz entre os muros de um condomínio, nos espaços heterotópicos do medo, da indiferença. Que lutam contra a obsessão pela segurança, que saem à noite com os pés nos chãos calçados ou nus, pavimentados ou não, da cidade. Vigiados ou não. Controlados ou não por câmeras, 
olhos e os pesadelos da securitização. Esses tipos que tramitam existência se aproximando da polis, pensando as cidades que lhes cabem, desacelerados dos signos capitalísticos, de seus mundos. Repito, não se trata de uma utopia, trata-se de olhar para o lado. A cidade não para de refazer-se. A cidade não para de contestar os ímpetos racionalizantes, o pensamento único e determinista seja de onde venha, dos arcanos de higienistas e eugenistas políticos. Ou da planificação molar de uma revolução controlável e domesticada. A cidade febril é indisciplinada e está fora de controle.

\section{Considerações finais: efeito joker, a cartada final}

A imagem do Coringa (2019) dançando nas escadarias intermináveis da cidade ameaçadora sintetiza boa parte do que dissemos até aqui. Sua reapropriação lúdica em meio à cidade febril, dançando em meio aos fluxos dos mascarados que tomam a cidade para si, ocupando ruas e afetos, liberando medos e frustrações, tornando a cidade uma imensa tela de desejos. A desarticulação da metrópole em seus aparatos institucionais e os seus fluxos de regulação, tomada de assalto por subjetividades insurgentes a paranoia da securitização, os endividamentos sucessivos e asfixiantes, o esvaziamento do político nos mecanismos tecnocráticos e suas capturas no binômio estado-mercado.

O filme de Todd Phillips (2019) mobiliza uma crítica contundente às máquinas e signos que alimentam as subjetividades da crise desde a explosão da bolha hipotecária do subprime (2007), colocando no centro do desdobramento o combate à sociedade do espetáculo. Em uma das suas cenas, o assassinato do apresentador de TV inflexiona a cartada final do embate entre a subjetividade descentrada do Coringa e a estética da tomada do espetáculo para si e a liberação dos mascarados na cidade. Como afirma Mendes (2018, p. 233), inspirado pela genealogia histórica do urbanismo proposta pela historiadora do urbano Françoise Choay,

[...] para compreender o urbanismo moderno é necessário perceber que o registro dos modelos utópicos passa a caminhar de mãos dadas com o ideal terapêutico que os gregos denominavam de pharmakon. É Cerdá, urbanista catalão, que aparece de jaleco branco para constituir a cidade como um objeto de intervenção científica e médica. A "cidade-doente", fruto da irrupção da urbanização industrial, apresenta-se como

revista entreideias, Salvador, v. 10, n. 1, p. 139-153, jan./abr. 2021 
fonte do caos, da desordem, dos vícios morais, da corrupção e das doenças contagiosas. É preciso intervir no espaço urbano da mesma forma que um médico, de posse de seu bisturi cirúrgico, corta, remodela, extirpa os elementos indesejáveis, transformando o corpo doente.

Na contramão do urbanismo científico e higienista, o personagem de Bob Kane inspirada em Victor Hugo, parece desterritorializar linhas aberrantes ao espaço de disciplina-controle. A retomada da cidade como obra de arte desencadeada pela dança ameaçadora dispara um fluxo de desejos que retiram os corpos da docilidade e da previsibilidade do ordenamento da população. Dobram os corpos e os espaços no tempo de uma nova curvatura em que os palhaços mascarados que tomam as ruas de Gotham, antecipam os mascarados que tomam as ruas durante a pandemia de COVID-19. Todo um trabalho das linhas que costuram novas segmentações, recompondo o cenário das lutas dos corpos em uma cidade do espetáculo adiado.

Classes duplamente perigosas como afirmou o historiador Chalhoub (2017), potenciais propagadoras de doenças e propensas à desobediência civil. Articuladas por essa demanda histórica que parece ser atualizada pela pandemia de COVID-19, as cidades não só são estufas de propagação do vírus por sua aglomeração, contato e proximidade de encontro, sobretudo, nos espaços da pobreza estrutural, como também espreitam a segurança pública em seu estoque sempre renovável de linhas de fuga à ordem e proliferação de levantes.

As utopias do urbanismo e da educação estiveram por largos anos de mãos dadas com o poder, não sem experimentarem convulsões e resistências diversas. Cabe entender tanto suas dimensões molares e moleculares e as segmentações que atualizam, seja nas segregações sociais, seja nas segregações espaciais, como também, seus modos de subjetivação do informe.

Assim, se há uma educação por vir depois do futuro, ela está inscrita no que é possível ver nas luzes bruxuleantes da fúria dos vaga-lumes que a sociedade do espetáculo adiado espoca no meio da noite. Algumas dessas contra-utopias e seu iluminismo das sombras arrasta nossos olhos para frestas que, se alargadas, desfazem a luz branca das distopias do poder.

Atravessando algumas dessas fogueiras difusas, elencamos algumas reverberações que a pandemia de COVID-19 evoca, como 
linhas abertas ao pensamento habitado por sua perspectiva e passível de formulações vindouras entre educação e cidade:

1) A pandemia não só suspende a sociedade do espetáculo, como abre novas brechas na produção de subjetividades em crise, forçando o pensamento a habitar a interioridade de outro ponto de vista. Habitar essa interioridade significa insistir numa percepção que nos leva ao deserto das intencionalidades. Um movimento aberrante de descentramento dos sujeitos e a composição de uma nova nuvem de virtuais. A fúria dos vaga-lumes, como dissemos acima, não encontra um mundo pronto, mas a possibilidade de constituir o comum na transmodalidade dos pontos de vista que desprende;

2) Aventar possibilidades de pensamento desde a interioridade do ponto de vista da pandemia que nos assola, estar à altura do mundo que criou, significa também apreender os quase-mundos que flutuam nessa experiência. Análise utópica da cidade em Lefebvre (2008). A existência de fenômenos, coisas e virtuais que nos colocaram no plano de imanência da pandemia, reivindicam outras economias, formas de proteção social, novas cidades e moradias, serviços de saúde ampliados, acesso e outras formas de fazer educação. Habitar o ponto de vista da pandemia desloca a temporalidade da política, necessitando acelerar tendências e formas inexistentes de atenção. O ponto de vista da pandemia faz ver e falar outras realidades, como germes que abrem possibilidades de criação, obras por fazer;

3) Não mais a clivagem entre a educação formal, não formal e informal. Suas divisões entre intencionalidades e espontaneidades. Suas ativações pedagógicas e territórios escolarizantes. O que o ponto de vista da pandemia deixa antever é o quase-mundo de uma educação informe, "[...] pensar se faz no entremeio, no interstício ou na disjunção do ver e do falar”. (CORAZZA, 2013, p. 76) A necessidade de pensar a circulação de saberes, produções científicas, novas fronteiras entre o dentro e o fora, seus isolamentos e linhas de força centrífugas, os entreatos da educação. A pandemia produziu um terremoto na educação em todo o mundo, colocou a nu as desigualdades e suas ficções. Não significa que a educação já não estivesse em um território sísmico, porém, o ponto de vista da pandemia intensificou a frequência mais baixa que não se escutava com tanta nitidez. O informe na educação é o despojamento dos clusters cognitivos que a jogam para o mesmo centro dos sujeitos, 
as mesmas questões e armadilhas críticas. A educação do informe é uma malha que provoca a pensar os diferentes pontos de vista que se deslocam de suas gordas razões e suas tarefas pesadas demais. O ponto de vista da pandemia cria intensificadores de realidade, torna mais reais as existências, desdobra pautas como a renda universal básica, os cadáveres ocultados dos epistemicídios, a precariedade sistêmica da uberização do trabalho, a mercantilização da saúde e da educação no binômio Estado-Mercado, os micro e macro fascismos e suas ingerências necropolíticas. Mover-se por uma educação do informe pode ser uma estratégia de circular o direito à cidade e à educação não só no âmbito do acesso ao já existente, mas a reinvenção da cidade e da educação em outros espaços e tempos por vir.

Portanto, três apontamentos que nos permitem perceber a necessidade de habitar o ponto de vista da pandemia (espécie de perspectivismo), exercitar uma nova atenção (suspensão do tempo do espetáculo) e a liberação de novas visualidades e enunciados do contemporâneo (educação do informe). Tal como a temporalidade definida pelo filósofo italiano, "perceber no escuro do presente essa luz que procura nos alcançar e não pode fazê-lo, isso significa ser contemporâneo". (AGAMBEN, 2013, p. 65) Efeito Joker da fúria dos vaga-lumes, encontrar o riso por trás das máscaras da cidade febril.

\title{
Spectacle society postponed: notes on education in the sick city
}

\begin{abstract}
This article aims to develop some notes on the impacts of the covid-19 pandemic on education. Part of the suspension of the characteristics of the spectacle society amid the changes brought about by the health crisis and its economic, social, cultural developments and, above all, in contemporary modes of subjectification. The new scenario sharpens the molar and molecular segmentation of debt, secutirization and the emptying of political bodies, further forcing the search for open territories and the need for other fields of visuality. Understanding the pandemic as a point of view, inhabiting the interiority of this perspective helps us to understand not only the shadows of residual modernity, but also the subjectivation processes that exercise other forms of attention, a kind of fury of fireflies in the famous image proposed by Pasolini. In addition to the dominant forms of education, it is this almost world of shapeless education that opens up with the current hell of the moment. Some of these against utopias and their shadow illumination drags our eyes to cracks that, if enlarged, undo the white light of utopias and dystopias of power. Crossing some of these diffuse bonfires, we list some reverberations that the covid-19 pandemic evokes, as lines open to thought violated by its perspective and subject to future formulations, what we call the "Joker" effect in the society of the delayed spectacle.
\end{abstract}


Keywords: Pandemic. Spectacular Society. Feverish City. Shapeless Education.

\title{
Sociedad del espectáculo aplazada: notas sobre la educación en la "ciudad febril"
}

\begin{abstract}
Resumen: Este artigo tiene como objetivo desarrollar algunas notas sobre los impactos de la pandemia covid-19 en la educación. Parte de la suspensión de las características de la sociedad del espectáculo en medio de los cambios provocados por la crisis de salud y sus desarrollos económicos, sociales, culturales y, sobre todo, en los modos contemporáneos de subjetivación. El nuevo escenario agudiza la segmentación molar y molecular de la deuda, la secutirización y el vaciado de los cuerpos políticos, lo que obliga aún más a la búsqueda de territorios abiertos y la necesidad de otros campos de visualización. Entender la pandemia como un punto de vista, habitar la interioridad de esta perspectiva nos ayuda a comprender no solo las sombras de la modernidad residual, sino también los procesos de subjetivación que ejercen otras formas de atención, una especie de furia de luciérnagas en la famosa imagen propuesta por Pasolini. Además de las formas dominantes de educación, es este cuasi-mundo de educación informe que se abre con el infierno actual del momento. Algunas de estas contra-utopías y su iluminación de la sombra arrastra nuestros ojos a grietas que, si se agrandan, deshacen la luz blanca de las utopías y las distopías del poder. Al cruzar algunas de estas hogueras difusas, enumeramos algunas reverberaciones que evoca la pandemia de COVID-19, como líneas abiertas al pensamiento violado por su perspectiva y sujeto a futuras formulaciones, 1o que 1lamamos el efecto "Joker" en la sociedad del espectáculo suspendido.
\end{abstract}

Palabras-clave: Pandemia. Sociedad del Espectáculo. Ciudad Febril. Educación del Informe.

\section{Referências}

AGAMBEN, G. O Que é o Contemporâneo? E Outros Ensaios. Chapecó: Argos, 2013.

BERARDI, F. Depois do Futuro. São Paulo: Ubu, 2019.

CASTRO, E. V. de.; DANOWSKI, D. Há Mundo Por Vir? São Paulo: Ed. Cultura e Barbárie, 2015.

CASSIANO, M.; FURLAN, R. O Processo de Subjetivação Segundo a Esquizoanálise. Revista Psicologia \& Sociedade,[s. 1.], v. 25, n. 2, p. 372378, 2013. Disponivel em: https://www.scielo.br/pdf/psoc/v25n2/14. pdf. Acesso em 16 out. 2020.

CHALHOUB, S. Cidade Febril. São Paulo: Ed. Cia das Letras, 2017.

CORAZZA, S. O que se Transcria em Educação? Porto Alegre: Ed. Supernova, 2013.

CORINGA. Direção: Todd Phillips. Produção: Todd Phillips, Bradley Cooper, Emma Tillinger Koskoff Village Roadshow Pictures, DC Films, 
Sikelia Productions, Joint Effort Productions, Green Hat Films, Estados Unidos da América, 2019, filme (122 min), DVD. Título original: Joker.

DEBORD, G. Sociedade do espetáculo. Rio de Janeiro: Contraponto, 2000.

DELEUZE, G. Tha deserta. São Paulo: Iluminuras, 2006.

DELEUZE, G. Crítica e clínica. São Paulo: Ed. 34, 2004.

DELEUZE, G.; GUATTARI, F. Mil platôs. São Paulo: Ed. 34, 2004. v. 3.

DELEUZE, G.; GUATTARI, F. Mil platôs. São Paulo: Ed. 34, 2005. v. 5.

DIDI-HUBERMAN, G. O que vemos, o que nos olha. São Paulo: Ed. 34, 2010.

DIDI-HUBERMAN, G. A sobrevivência dos vaga-lumes. Belo Horizonte: Ed. 34, 2011.

GUATTARI, F. Caosmose. Rio de Janeiro: Ed. 34, 2000.

GUATTARI, F. As três ecologias. Campinas: Papirus, 2001.

HARVEY, D. Cidades rebeldes. São Paulo: Martins Fontes, 2014.

LAPOUJADE, D. Existências cínimas. São Paulo: N-1, 2017.

LAZZARATO, M. As revoluções do capitalismo. Rio de Janeiro: Record, 2008.

LAZZARATO, M. Signos, máquinas, subjetividades. São Paulo: Sesc: N-1, 2014 .

LAZZARATO, M.; NEGRI, A. Trabalho imaterial: formas de vida e produção da subjetividade. Rio de Janeiro: DPEA, 2001.

LEFEBVRE, H. Revolução urbana. Belo Horizonte: Ed. UFMG, 2008.

LEFEBVRE, H. Espaço e política. Belo Horizonte: Ed. UFMG, 2008.

LEFEBVRE, H. O direito à cidade. São Paulo: Centauro, 2001.

JAMESON, F. Pós-Modernismo: a lógica cultural do capitalismo tardio. São Paulo: Ática, 2000.

MENDES, A. Vertigens de junho. Rio de Janeiro: Autografia, 2018.

NEGRI, A. Para uma definição ontológica de multidão. Revista Lugar Comum, Rio de Janeiro, p. 15-16, 2013. Disponivel em: http:// uninomade.net/wp-content/files_mf/113103120455output19-20.pdf. Acesso em: 3 maio 2015.

NEGRI, A. Rem Koolhaas: Junkspace e metrópole biopolítica. Revista Global Brasil, Rio de Janeiro, set. 2014. Disponivel em: http://uninomade.net/tenda/rem-koolhaas-junkspace-e-metropolebiopolitica/. Acesso em 05 Mai 2015.

NEGRI, A. Cinco lições sobre império. Rio de Janeiro: DPEA, 2003.

NEGRI, A.; HARDT, M. Multidão: guerra e democracia na era do Império. Rio de Janeiro: Record, 2005. 
NEGRI, A.; HARDT, M. Declaração: isto não é um manifesto. São Paulo: Sesc: N-1, 2014.

PELBART, P. O avesso do niilismo. São Paulo: N-1, 2014.

PELBART, P. Vida capital. São Paulo: Iluminuras, 2003.

REVEL, J. Dicionário Foucault. São Paulo: Forense, 2011.

RUFINONI, P. R. Oswaldo Goeldi: iluminação, ilustração. São Paulo:

Cosac Naify, 2006.

TANIZAKI, J. Em louvor das sombras. São Paulo: Companhia das Letras, 2017.

WISNIK, G. Dentro do nevoeiro. São Paulo: Ubu, 2018.

Submetido em: $20 / 07 / 2020$

Aceito em: 28/10/2020 